\title{
Propagation of TE and TM polarised light through smoothed sixty degree bends in planar photonic crystal waveguides
}

Frandsen, Lars Hagedorn; Borel, Peter Ingo; Thorhauge, Morten; Cheng, J.; Kampanis, M.; Kristensen, Martin; Lavrinenko, Andrei; Zhuang, Yanxin; Chong, H.M.H.

\section{Published in: \\ CLEO/Europe}

Link to article, DOI:

10.1109/CLEOE.2003.1313734

Publication date:

2003

Document Version

Publisher's PDF, also known as Version of record

Link back to DTU Orbit

Citation (APA):

Frandsen, L. H., Borel, P. I., Thorhauge, M., Cheng, J., Kampanis, M., Kristensen, M., Lavrinenko, A., Zhuang, Y., \& Chong, H. M. H. (2003). Propagation of TE and TM polarised light through smoothed sixty degree bends in planar photonic crystal waveguides. In CLEO/Europe (Vol. CM4-1-FRI). CLEO/Europe. https://doi.org/10.1109/CLEOE.2003.1313734

\section{General rights}

Copyright and moral rights for the publications made accessible in the public portal are retained by the authors and/or other copyright owners and it is a condition of accessing publications that users recognise and abide by the legal requirements associated with these rights.

- Users may download and print one copy of any publication from the public portal for the purpose of private study or research.

- You may not further distribute the material or use it for any profit-making activity or commercial gain

- You may freely distribute the URL identifying the publication in the public portal 


\title{
Propagation of TE and TM polarised light through smoothed sixty degree bends in planar photonic crystal waveguides
}

\author{
L.H. Frandsen, P.I. Borel, M. Thorhauge, J. Cheng, M. Kampanis, M. Kristensen, A. Lavrinenko, Y. Zhuang, \\ Research Center COM, Technical University of Denmark, Bldg. 345 west, DK-2800, Kgs. Lyngby, Denmark \\ H.M.H. Chong \\ Department of Electronics and Electrical Engineering, Glasgow University, Glasgow G12 8LT, Scotland, UK
} Low-Ioss straight photonic crystal waveguides (PCWs) have previously been demonstrated [1]. In this work, bends in
planar $\mathrm{PCW}$ are investigated by introducing two smoothed $60^{\circ}$ bends each
having one hole relocated as shown in the $\mathrm{SEM}$ image to the right. Holes, in a
$\mathrm{SiO}_{2} / \mathrm{Si} / \mathrm{SiO} \mathrm{O}_{2}$ trilayer film, with diamer $\mathrm{D}_{\text {glass }}=76 \Lambda$ are arranged in a
triangular lattice with $\Lambda=428 \mathrm{~nm}$ constructed using e-beam lithography, reactive
ion etching, and thermal oxidation. The PCWs are defined by leaving out single
rows of holes. The fabricated $60^{\circ}$ bends are separated by $20 \Lambda$. In and out
coupling of light to the PCWs is obtained utilising tapered ridge waveguides and
tapered lensed fibres. Transmission spectra are recorded for both the TE and TM
polarisation with an optical spectrum analyser by using two LED sources
centred at $1330 \mathrm{~nm}$ and $1550 \mathrm{~nm}$. The measured spectra are compared to $3 \mathrm{D}$
FDTD simulations performed on a PCW containing two smoothed $60^{\circ}$ bends
separated $7 \Lambda$ by using an improved version of the ONYX-2 code [2]. In order to extract the bend losses for the two consecutive $60^{\circ}$ bends the experimental and calculated spectra for the smoothed $60^{\circ}$ bends are normalised to straight PCWs of the same length. The results are, for a given polarisation, shown in the figure below in the wavelength ranges, where the lowest propagation losses for straight PCWs were measured and calculated.
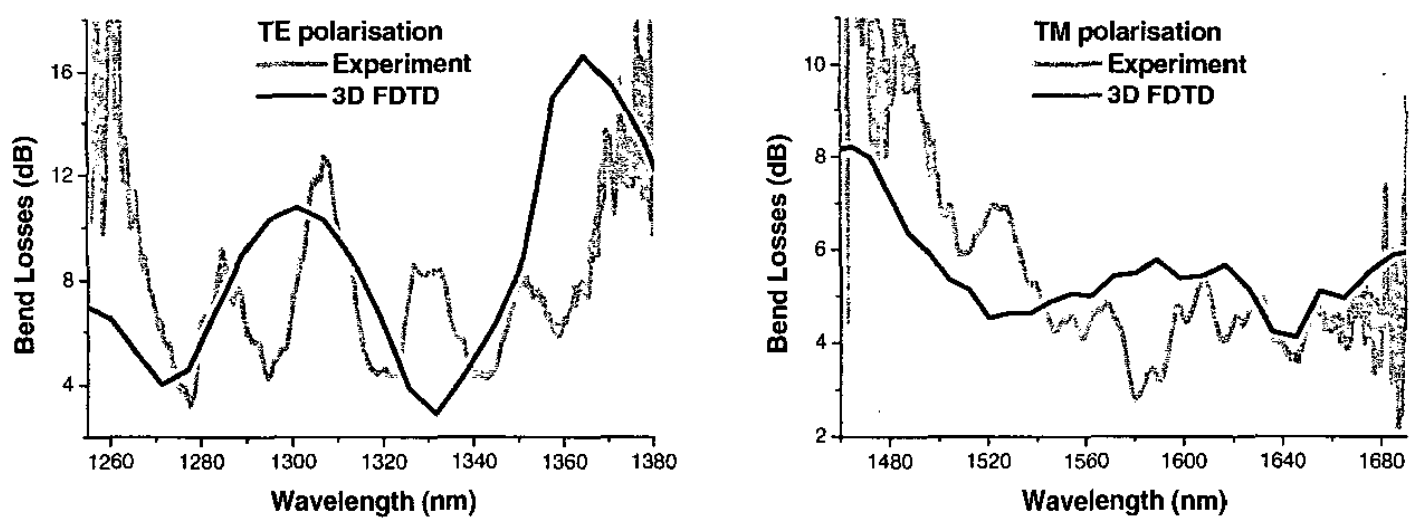

The oscillations observed in the spectrum for the TE polarisation have conclusively been identified as Fabry-Perot resonances by recording experimental spectra for PCWs having different lengths $(20-40 \Lambda)$ of the intermediate straight PCW connecting the two bends. The Fabry-Perot cavity oscillations in the measured and simulated spectra for the TE polarisation are found to be in good agreement, when the different lengths of the intermediate straight PCW are taken into account. Thus, it is seen that the 3D FDTD simulations successfully explain the observed bend losses both for the TE and TM polarisations. Losses as small as $2 \mathrm{~dB}$ are observed per bend for the TE polarisation. For the TM polarisation the average loss per bend is experimentally found to be $2.1 \pm 0.3 \mathrm{~dB}$ in the wavelength range $1540-1680 \mathrm{~nm}$. Hence, the smoothened bends work equally well for the TE and TM polarisation even though band calculations have shown that propagation for the TM polarization take place below the valence band in the investigated wavelength range. Further experiments have shown that modifying the bends as illustrated in the top figure improves the transmission per bend by $4 \mathrm{~dB}$ for both the TE polarisation and TM polarisation compared to un-smoothened sharp $60^{\circ}$ bends.

[1] J. Arentoft. T. Søndergaard. M. Kristensen. A. Boltasseva. M. Thorhauge, and L. Frandsen. "Low-loss silicon-on-insulator photonic crystal waveguides." Electron. Lett. 38. 274-275 (2002).

[2] A.J. Ward and J.B. Pendry. "A program for calculating photonic band structures, Green's functions and transmission/reflection coefficients using a non-orthogonal FDTD method". Comp. Phys. Com. 128, 590-621 (2000). 